\title{
Infecção experimental de Salmonella Saintpaul em Periquito- australiano (Mellopsitacus undulatus)
}

\section{Experimental inoculation of Salmonella Saintpaul in budgerigars (Melopsittacus undulatus)}

\author{
Elisângela de Souza Lopes ${ }^{1}$, Amanda Ribeiro de Sousa ${ }^{2}$, Erica Maria Sousa de Queiroz \\ Campos ${ }^{2}$, Bruno Pessoa Lima ${ }^{2}$, Adson Ribeiro Marques ${ }^{2}$, William Cardoso Maciel ${ }^{2 *}$
}

\begin{abstract}
RESUMO
O objetivo desse estudo foi observar em periquitos australianos (Mellopsitacus undulatus) inoculados com cepa de Salmonella Saintpaul a presença de sinais clínicos, excreção do microrganismo e as possíveis alterações macroscópicas em órgão acarretadas pela infecção bacteriana. Foram estudados dois grupos experimentais que receberam inóculos via gavagem com determinada concentração bacteriana. Após a inoculação, foram realizadas análises microbiológicas, para a detecção de patógenos de suabe cloacal e de amostras de fezes. No último dia, as aves foram eutanasiadas para a análise de órgãos. Durante o período experimental não foram observadas mortalidade ou detecção de sinais clínicos, embora tenha sido possível observar a positividade do microrganismo nas fezes, suabes cloacais e órgãos das aves que receberam a maior dose de concentração. Nos dois grupos foram observadas alterações macroscópicas. Este estudo mostrou que periquitos australianos infectados com alta concentração bacteriana não apresentaram sinal clínico da doença. Porém, essas aves são susceptíveis à invasão bacteriana nos órgãos internos e podem disseminar o patógeno no meio ambiente.
\end{abstract}

Palavras-chave: Inoculação; Salmonella Saintpaul; Mellopsitacus undulatus; Concentração bacteriana; Sinais clínicos.

\begin{abstract}
The aim of this study was to observe in budgerigars (Mellopsitacus undulatus) inoculated with a strain of Salmonella Saintpaul the presence of clinical signs, excretion of the microorganism and possible macroscopic changes in the organ caused by bacterial infection. Two experimental groups that received inoculation via gavage with a certain bacterial concentration were studied. After inoculation, microbiological analyzes were performed to detect pathogens in cloacal swab and in stool samples. On the last day, the birds were euthanized for organ analysis. During the experimental period, no mortality or detection of clinical signs were observed, although it was possible to observe the positivity of the microorganism in the feces, cloacal swabs and organs of the birds that received the highest concentration
\end{abstract}

\footnotetext{
${ }^{1}$ Biolab Clínica e Laboratório Veterinário LTDA, Fortaleza-CE, Brasil

${ }^{2}$ Universidade Estadual do Ceará, Faculdade de Medicina Veterinária, UECE.

*E-mail: william.maciel@uol.com.br.
} 
dose. In both groups, macroscopic changes were observed. This study showed that budgerigars infected with high bacterial concentration showed no clinical sign of the disease. However, these birds are susceptible to bacterial invasion of internal organs and can spread the pathogen in the environment.

Keywords: Inoculation; Salmonella Saintpaul; Mellopsitacus undulatus; Bacterial concentration; Clinical signs.

\section{INTRODUÇÃO}

Os artigos devem conter no máximo 10 mil palavras em folha tamanho A4. As margens laterais devem estar em $3 \mathrm{~cm}$ e as margens superior e inferior, $2,5 \mathrm{~cm}$.

Nos últimos anos, alguns estudos relataram o isolamento de diferentes sorotipos de Salmonella em psitacídeos de cativeiro que foram apreendidos no comércio ilegal de animais silvestres (MARIETTO-GONÇALVES et al., 2010; LOPES et al., 2014). S. ser. Typhimurium é o sorotipo mais frequentemente relatado em estudos realizados com psitacídeos, que também parece ser o mais virulento (VIGO et al., 2009). No entanto, outros sorotipos importantes têm sido citados em estudos com aves silvestres, como Salmonella Saintpaul (RECHE et al., 2003; SOUSA et al., 2010).

O sorotipo Saintpaul, inserido entre as Salmonellas paratíficas, está associado a surtos de toxinfecções causadas pela ingestão de alimentos e água contaminados, sendo reconhecido como patógeno responsável por causar diarreia, enterite e até morte em humanos (BEHRAVESH et al., 2011). Relatos científicos envolvendo aspectos patogênicos em aves são raros. Na Nova Zelândia no ano de 2011, foi descrito um caso de mortalidade de Hihi (Notiomystis cincta) de vida livre causado por infecção por Salmonella Saintpaul, e surgiram indícios que poderia ter sido trazida por turistas que visitaram a área (Alley et al., 2012).

Salmonella Saintpaul foram relatadas em estudo realizado por Lopes et al. (2014) em um Ara chloropterus criado em cativeiro. No entanto, não existem estudos descrevendo aspectos patogênicos deste sorotipo em psitacídeos. Portanto, este estudo teve como objetivo avaliar periquitos (Mellopsitacus undulatus) inoculados com uma cepa de Salmonella Saintpaul quanto a sinais clínicos, excreção bacteriana e alterações macroscópicas em órgãos.

\section{MATERIAL E MÉTODOS}

Este estudo foi realizado no Laboratório de Estudos Ornitológicos (LABEO), da Universidade Estadual do Ceará (UECE) e foi aprovado pelo Comitê de Ética para Uso 
de Animais da Universidade Estadual do Ceará (CEUA/UECE) com o seguinte número de protocolo: 127697942.

Periquitos adultos machos $(n=3)$ e fêmeas $(n=3)$ foram usados neste estudo. Inicialmente, as aves não apresentavam sinais clínicos da doença e foram analisadas quanto à presença de Salmonella spp. segundo Sousa et al. (2010).

As aves foram mantidas em gaiolas de arame galvanizado $(22 \times 21 \times 16 \mathrm{~cm}) \mathrm{e}$ distribuídas em três indivíduos por grupo, formando dois grupos. Os grupos foram denominados A e B, que receberam por gavagem Salmonella Saintpaul resistente ao ácido nalidíxico $\left(\mathrm{SSNal}^{\mathrm{r}}\right)$ na concentração bacteriana de $1,2 \times 10^{9}$ e $7,7 \times 10^{4} \quad \mathrm{UFC} / \mathrm{mL}$, respectivamente. Durante o experimento, as aves tiveram livre acesso a água esterilizada e ração. A temperatura $\left(25^{\circ} \mathrm{C}\right)$ e horas de luz $(16 \mathrm{~h} /$ dia) foram controladas. A cepa de Salmonella Saintpaul utilizada no estudo foi originalmente isolada de um papagaio-deasa-laranja (Amazona amazonica) oriundo do Centro de Triagem de Animais SilvestresCETAS-CE (Lopes et al., 2015). Para a preparação do inóculo, a cepa foi cultivada e submetida a diluições em séries de acordo com a técnica de Miles e Misra (1938).

Uma vez inoculadas, as aves foram monitoradas diariamente durante dez dias consecutivos quanto a sinais clínicos, além da eliminação de $\mathrm{SSNal}^{\mathrm{r}}$ nas fezes, contagem de unidades formadoras de colônias (UFC) e suabes cloacais. Aos 10 dias pós-inoculação (DPI), todas as aves foram eutanasiadas com injeção de cetamina IV para investigar a presença de SSNal ${ }^{\mathrm{r}}$ no fígado, baço e intestino. As análises de contagem de UFC nas fezes e presença de Salmonella em amostras de suabes e órgãos cloacais foram realizadas de acordo com Albuquerque et al. (2013).

O monitoramento microbiológico em suabes e órgãos cloacais foi realizado individualmente, enquanto a contagem de UFC nas fezes foi realizada em uma amostra agrupada por gaiola.

\section{RESULTADOS E DISCUSSÃO}

As concentrações bacterianas inoculadas oralmente em periquitos foram suficientes para realizar a contagem de UFC nas fezes coletadas entre um e oito DPI no grupo A o qual recebeu o maior inóculo. Contudo, aves que receberam a menor concentração não apresentaram crescimento de $\mathrm{SSNal}^{\mathrm{r}}$ em nenhuma amostra, o qual foi também negativo quando usado enriquecimento seletivo (Tabela 1). 
Tabela 1. Contagem de Unidades Formadoras de Colônia de Salmonella Saintpaul por grama de fezes (UFC/g) em amostras agrupadas de periquitos infectados experimentalmente e observados por dez dias pós-inoculação

Concentração Dias pós-inoculação

(A) $10^{9}$

\begin{tabular}{cccccccccc}
\hline D1 & D2 & D3 & D4 & D5 & D6 & D7 & D8 & D9 & D10 \\
\hline $1 \times 10^{4}$ & $1 \times 10^{3}$ & $2 \times 10^{4}$ & $1 \times 10^{3}$ & $2 \times 10^{5}$ & $9 \times 10^{3}$ & $1 \times 10^{5}$ & $1 \times 10^{6}$ & - & -
\end{tabular}

(B) $10^{4}$

Similar à contagem de UFC em fezes, amostras de suabes cloacais coletadas de periquitos no grupo B também foram negativas em todos os DPI para SSNal ${ }^{r}$. Entretanto, as aves do grupo A foram positivas do segundo dia ao nono pós inoculação DPI (Tabela 2). A liberação de bactérias em suabes cloacais e fezes devem estar associadas com a concentração do inóculo. Esses resultados corroboram com outros estudos, que demonstraram que inóculos de aves com concentração bacteriana mais elevada de Salmonella apresentaram maior índice de isolamento (ISHOLA et al., 2009; ALBUQUERQUE et al., 2013).

Tabela 2. Amostras positivas de suabes cloacais de Salmonella Saintpaul de periquitos infectados experimentalmente e monitorados dentro de um período de dez dias

\begin{tabular}{ccccccccccc}
\hline Concentração & \multicolumn{10}{c}{ Dias pós-inoculação } \\
\cline { 2 - 10 } & D1 & D2 & D3 & D4 & D5 & D6 & D7 & D8 & D9 & D10 \\
\cline { 2 - 10 } (A) $10^{9}$ & - & $3 / 3$ & $3 / 3$ & $3 / 3$ & $3 / 3$ & $3 / 3$ & $3 / 3$ & $3 / 3$ & $3 / 3$ & - \\
(B) $10^{4}$ & - & - & - & - & - & - & - & - & - & - \\
\hline
\end{tabular}

Todos os órgãos do grupo A foram positivos em algumas amostras, ocorrendo uma vez no baço e duas vezes no fígado e intestino (Tabela 3). Esse resultado é similar ao encontrado por Albuquerque et al (2013), que inoculou concentrações bacterianas diferentes de Salmonella Enteritidis em Columba livia e verificou que apenas o grupo com o inóculo de maior concentração foi positivo em amostras do fígado e baço.

Tabela 03. Presença de Salmonella Saintpaul nos órgãos de periquitos depois de dez dias pósinoculação

\begin{tabular}{lccc}
\hline Órgãos & \multicolumn{3}{c}{ Concentração bacteriana } \\
\cline { 2 - 3 } & $10^{9}(\mathrm{~A})$ & $10^{4}(\mathrm{~B})$ \\
Fígado & $2 / 3$ & - \\
Baço & $1 / 3$ & - \\
Intestino & $2 / 3$ & - \\
\hline
\end{tabular}


Alterações macroscópicas típicas de salmonelose foram observadas em ambos os grupos. Todas as aves no grupo A apresentaram hemorragia intestinal, enterite leve, o fígado apresentou-se pálido, friável e congesto, foi observado pericardite e esplenomegalia com focos necróticos. Aves do grupo B apresentaram alterações macroscópicas menos frequentes e necrose no baço foram observadas em duas aves. Outras lesões foram detectadas apenas uma vez, as quais foram: enterite leve, nefrite hemorrágica, pericardite, esplenomegalia com foco necrótico e fígado pálido e congesto.

Durante o experimento, não houve mortalidade ou sinais clínicos. Um estudo feito por Gast e Beard (1989) demonstrou resultados similares, o que pode explicar nossos achados. Esses pesquisadores inocularam Salmonella Typhimurium via oral em pintos de corte e observaram altas taxas de isolamento no fígado e no baço, mesmo em grupos com baixa ou nenhuma taxa de mortalidade. Eles propuseram que o desenvolvimento clínico da doença pode exigir mais que a passagem de alguns microorganismos pela barreira intestinal, enquanto outros fatores de virulência também devem ser importantes para interagir com os mecanismos de defesa e determinar o curso da infecção.

Não há nenhum relato de alterações macroscópicas em psitacídeos infectados com $S$. Saintpaul. Nesse estudo as lesões foram similares a relatos com outros sorotipos infectando psitacídeos. Estudos de Vigo et al. (2009) e Piccirillo et al (2010) com psitacídeos naturalmente infectados por Salmonella Typhimurium descreveram esplenomegalia, hepatomegalia, enterite leve e fígado friável. Lesões típicas de salmonelose como, necrose no fígado e baço, esplenomegalia e hepatomegalia foram relatadas em passeriformes encontrados mortos na Noruega (REFSUM et al., 2003).

Em psitacídeos, Salmonella Saintpaul foi relatada apenas uma vez e descrita na pesquisa por Lopes et al. (2014) em aves de criação em cativeiro no estado do Ceará, Brasil. Não há estudos nos aspectos patogênicos desse sorotipo em psitacídeos. Entretanto, sabe-se que salmonelose causada por microorganismos paratifóides, em geral, pode não apresentar sintomatologia em psitacídeos, que podem se tornar carreadores assintomáticos do microorganismo (MARIETTO-GONÇALVES et al., 2010). Todavia, alguns fatores como o sorotipo, concentração bacteriana, idade das aves, estresse físico e ambiental pode tornar o indivíduo suscetível à doença (DAOUST e PRESCOTT, 2007) e consequentemente a manifestação clínica. 


\section{CONCLUSÃO}

Concentrações bacterianas de $1.2 \times 10^{9}$ e $7.7 \times 10^{4} \mathrm{UFC} / \mathrm{mL}$ de Salmonella Saintpaul inoculadas via oral não causam sinais clínicos ou mortalidade em periquitos durante o período avaliado. Contudo, o inóculo mais alto induziu a disseminação bacteriana nas fezes por, pelo menos, oito dias pós-inoculação.

\section{AGRADECIMENTOS}

Agradecemos ao Conselho Nacional de Desenvolvimento Científico e Tecnológico (CNPq) e ao Laboratório de Estudos Ornitológicos (LABEO/FAVET/UECE) pelo apoio nesse estudo.

\section{REFERÊNCIAS}

ALLEY, M.R., WALKER, L., JAKOB-HOFF, R.M., POTTER, J.S., JACKSON, B.H., HUNTER, S.A. Salmonella Saintpaul Identified as a Cause of Mortalities in Birds on Tiritiri Matangi Island. Kokako, v. 19, n.39, p.10, 2012.

ALBUQUERQUE, Á.H., CARDOSO, W.M., TEIXEIRA, R.S.C., LOPES, E.S., SALES, R.J.P.F., HORN, R.V., ROCHA-E-SILVA, R.C., BEZERRA, W.G.A., GOMES-FILHO, V.J.R. Dissemination of Salmonella Enteritidis by ExperimentallyInfected Pigeons. Brazilian Journal Poultry Science, v.15, n.3, p.169-286, 2013.

BEHRAVESH, C.B., MODY, R.K., JUNGK, J., GAUL, L., REDD, J.T., CHEN, S., COSGROVE, S., HEDICAN, E., SWEAT, D., HAUSER, L.C., SNOW, S.L., HANSON, H., NGUYEN, T.A., SODHA, S.V., BOORE, A.L., RUSSO, E., MIKOLEIT, M., THEOBALD, L., SMIDTH, P.G., HOEKSTRA, R.M., ANGULO, F.J., SWERDLOW, D.L., TAUXE, R.V., GRIFFIN, P.M., WILLIAMS, I.T. Outbreak of Salmonella Saintpaul Infections Associated with Raw Produce. New England Journal Medicine, v.364, n.10, p. 918-927, 2011.

DAOUST, P.Y., PRESCOTT, J.F. Salmonellosis. In: THOMAS, N.J., HUNTER, D.B., ATKINSON, C.T. Infectious diseases of wild birds. Blackwell, Ames, Iowa, 2007. 491p.

GAST, R.K., BEARD, C.W. Age-Related Changes in the Persistence and Pathogenicity of Salmonella typhimurium in Chicks. Poultry Science, v.68, n.11, p. 1454-1460, 1989.

ISHOLA, O.O. Effects of challenge dose on faecal shedding of Salmonella Enteritidis in experimental infected chickens. African Journal of Biotechnology, v.8, n.7, p.13431346, 2009.

LOPES, E.S., MACIEL, W.C., ALBUQUERQUE, A.H., TEIXEIRA, R.S.C., SALLES, R.P.R., BEZERRA, W.G.A., ROCHA-E-SILVA, R.C., LIMA, S.V.G., SALES, R.J.P.F., VASCONCELOS, R.H. Isolation of Salmonella spp. in captive Psittaciformes 
from zoos and a commercial establishment of Fortaleza, Brazil. Arquivo Brasileiro Medicina Veterinária Zootecnia, v.66, n.3, p. 965-968, 2014.

LOPES, E.S., MACIEL, W.C., ALBUQUERQUE, A.H., NISHI, D.M., BEZERRA, W.G.A., HORN, R.V., LIMA, B.P., MARIETTO-GONÇALVES, G.A., TEIXEIRA, R.S.C. Prevalence and Antimicrobial resistance profile of Enterobacteria isolated from psittaciformes of illegal wildlife trade. Acta Scientiae Veterinariae, v.43, p.1-9, 2015.

MARIETTO-GONÇALVES, G.A., ALMEIDA, S.M., LIMA, E.T., OKAMOTO, A.S., PINCZOWSKI FILHO, R.L.A. Isolation of Salmonella enterica Serovar Enteritidis in Blue-Fronted Amazon Parrot (Amazona aestiva). Avian Disease, v.54, n.1, p. 151-155, 2010.

MILES, A.A., MISRA, S.S., IRWIN, J.O. The Estimation of the bactericidal power of the blood. The Journal of Hygiene, v.38, n.6, p. 732-749, 1938.

PICCIRILLO, A., MAZZARIOL, S., CALIARI MENANDRO, M.L. Salmonella Typhimurium Phage Type DT160 Infection in Two Moluccan Cockatoos (Cacatua moluccensis): Clinical Presentation and Pathology. Avian Disease, v.54, n.1, p.131$135,2010$.

RECHE, M.P., JIMÉNEZ, P.A., ALVAREZ, F., RÍOS, J.E.G., ROJAS, A.M., PEDRO, P. Incidence of Salmonellae in Captive and Wild Free-Living Raptorial Birds in Central Spain. Journal Veterinary Medical Science, v.50, n.1, p. 42-44, 2003.

REFSUM, T., VIKOREN, T., HANDELAND, K., KAPPERUD, G., HOLSTAD, G. Epidemiologic and pathologic aspects of Salmonella Typhimurium infection in passerine birds in norway. Journal Wildlife Disease, v.39, n.1, p. 64-72, 2003.

SOUSA, E., WERTHER, K., BERCHIERI JUNIOR, A. Assessment of Newcastle and infectious bronchitis pathogens, and Salmonella spp. in wild birds captured near poultry facilities. Arquivo Brasileiro de Medicina Veterinária e Zootecnia, v.62, n.1, p. 219$223,2010$.

VIGO, G.B., ORIGLIA, J., GORNATTI, D., PISCOPO, M., SALVE, A., CAFFER, M.I., PICHEL, M., BINSZTEIN, N., LEOTTA, G.A. Isolation of Salmonella Typhimurium from dead blue and gold macaws (Ara ararauna). Avian Disease, v.53, n.1, p.135-138, 2009. 